\title{
Tendências contemporâneas da geografia política e da geopolítica*
}

\section{Stéphane Rosière}

\section{Introdução}

Os nomes "geografia política” e "geopolítica” são usados por muitos pesquisadores, mas com métodos e finalidades, às vezes, muito diferentes. Este capítulo pretende questionar o uso desses rótulos que implicam em posicionamentos científicos e políticos. Este capítulo será dividido em três partes: primeiro gostaria de apresentar a geografia política e a geopolítica vistas da França, numa visão que enfatiza os tempos longos e sublinhando como os efeitos do "contexto" (guerras, tensões internacionais) foram sensíveis no florescimento dessas disciplinas (1). Em seguida este capítulo destaca a fragmentação contemporânea da geografia política e da geopolítica, destacando o caso da França, mas que não é muito diferente do que está acontecendo em outras partes do mundo (2). Finalmente, esta apresentação examina a dominação contemporânea da geopolítica crítica como uma transformação epistemológica fundamental que tem, porém, alguns excessos que parecem perigosos (3).

\section{A Geografia política e geopolítica vistas da França}

Quando Friedrich Ratzel publica seu livro Politische Geographie em 1897, sua reflexão não suscita entusiasmo na França. Paul Vidal de la Blache ${ }^{1}$ reconhece a importância da obra de seu colega alemão e correspondendo-se com Ratzel, ele próprio escreve vários artigos de geografia política. (Sanguin, 1988). No entanto, a recepção deste primeiro livro de "geografia política" é um tanto incerta. Como de hábito, o contexto político (e se poderia dizer "geopolítico") é decisivo - toda a ciência se desenvolve em um determinado ambiente político e é influenciada por ele. No entanto, o contexto dos primeiros desenvolvimentos da Geografia Política é o da guerra e da luta pela liderança na Europa continental entre a França e a Alemanha. Os dois países entram em guerra em 1870 e a Primeira Guerra Mundial ocorre 17 anos após a publicação deste livro. Assim, no início do século 20, a Geografia Política é percebida, antes de tudo, na França como uma ferramenta do nacionalismo alemão. Esta recepção inicial bastante negativa pesou fortemente sobre o desenvolvimento da geografia política na França.

Quando a Geopolitik aparece nos anos 20 na Alemanha, cientistas franceses têm um relacionamento ainda mais tenso com essa nova disciplina. A "geopolítica" defendida por Karl Haushofer, especialmente no contexto da

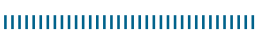

* Tradução do francês: Aldomar Arnaldo Rückert.

1 Paul Vidal de la Blache (1845-1918) é considerado como o fundador da geografia francêsa acadêmica (universitária).

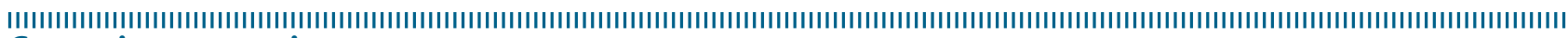
Como citar este artigo:

ROSIÈRE, Stéphane. “Tendências contemporâneas da geografia política e da geopolítica". In: RÜCKERT, A. A.; SILVA, A. C. P. da; SILVA, G. de V. (Orgs.). Geografia Política, Geopolítica e Gestão do Território: integração sul-americana e regiões periféricas. Porto Alegre: Editora Letra1, 2018, p. 87-95 
Zeitschrift für Geopolitik ${ }^{2}$, a revista dirigida por ele e que é publicada de 1923 a 1944, parece perigosa para eles. Para os franceses, a Geopolítica era, antes de tudo, uma ferramenta do imperialismo alemão. Isto é o que disse Albert Demangeon em 1932: "A geopolítica é um complô, uma máquina de guerra. Se ela quiser estar entre as ciências, é hora que retorne à geografia política”. (Demangeon, 1932). O mundo "acadêmico" tolerava mal esses novos desenvolvimentos na geografia. Ainda muito menos após a morte de Vidal de la Blache em abril de 1918, pois a geografia francesa era orientada, vigorosamente, por Emmanuel de Martonne para a geomorfologia. Naquele momento, a geografia física é central, a geografia humana se torna secundária e a geografia política é marginalizada (embora De Martonne tenha participado amplamente no desenho das novas fronteiras europeias produzidas pela Conferência da $\mathrm{Paz}$ em Paris em 1919-20). Como resultado, muito poucos pesquisadores franceses trabalham em geografia política ou geopolítica antes da Segunda Guerra Mundial. Podemos citar as exceções de André Siegfried, que funda a geografia eleitoral (Siegfried, 1913) ou Jacques Ancel, que publica o livro Géopolitique em 1936. Mas, esses são casos isolados, e esses pesquisadores não trabalhavam na Universidade, mas no Instituto de Estudos Políticos de Paris (Science-Po).

Após a Segunda Guerra Mundial, os geógrafos franceses são muito influenciados pelo marxismo. Eles desenvolvem uma geografia estruturalista, que quer ser também, claramente, um auxílio à ação, é uma "geografia ativa" - seguindo o título de um livro editado por Pierre George (George et al., 1964). Essa geografia renovada é principalmente econômica e social. Ela depende menos do conhecimento do campo, como nos dias de Vidal ou Martonne, do que das estatísticas. A Demogeografia (termo que caiu em desuso desde então) lançado por Pierre George em vez da antiga "geografia humana" (George, 1951) é uma boa ilustração dessa abordagem. Esta geografia se quer objetiva e científica, não tem nada a ver com uma

IIIIIIIIIIIIIIIIIIIIIIIIIIIIIIIIIII

2 Zeitschrift für Geopolitik: Revista de Geopolítica, em português. reflexão sobre potência ou o poder - especialmente porque que a filiação ao Partido Comunista (que é o caso de Pierre George, Jean Dresch ou Yves Lacoste ) é pouco propícia ao debate sobre questões de poder, o que é um eufemismo.

Neste contexto, com exceção da pesquisa de Jean Gottmann, que vive principalmente nos países anglo-saxões, mas continua a publicar em francês (ver seu livro La politique des Etats et leur géographie, publicado em 1952), é preciso aguardar a década de 1970 para que as coisas evoluam e que a geografia política e especialmente a geopolítica sejam consideradas na França com seriedade.

\section{Mudanças dos anos 1960-70}

Na sequência do reexame epistemológico, filosófico e político dos anos de 60 (nascimento do pós-modernismo), a questão do poder foi abordada frontalmente por Yves Lacoste a partir da segunda metade da década de 1970. Yves Lacoste (que foi um dos co-autores do livro "Geografia Ativa" mencionada acima) desempenha um papel decisivo na reabilitação da geopolítica na França e muitas vezes é o único autor francês conhecido na temática.

Este militante comunista, nascido no Marrocos, favorável à independência da Argélia (e, como tal, ameaçado de morte durante a guerra na Argélia), reabilita uma forma de "geografia radical" que ele chama de geopolítica. A utilização do termo "geopolítica" por Yves Lacoste provoca uma grave disputa e ruptura com seu antigo diretor de tese (Pierre George) que pode ser explicada por uma combinação de circunstâncias relacionadas, em parte pelo menos, à reflexão geopolítica conduzida no Brasil. De fato, a antiguidade do pensamento geopolítico no Brasil constitui uma originalidade (Costa, 1992; Albuquerque, 2011; Bohou, 2007, Rosière, 2013a), desde o período entre-guerras, particularmente através dos vínculos entre o Brasil e a Alemanha, quando se desenvolve uma escola de geopolítica, com raízes ratzelianas e que conhece, em seguida, um desenvolvimento autônomo (Carvalho 1929, Backhauser 1933, Delgado de Travassos 1935, etc.) Elemento importante do contexto: a palavra geopolítica não era tabu no 
Brasil, como era na França, especialmente depois de 1945.

A descoberta da geopolítica por Yves Lacoste deve à influência de Josué de Castro (1908-1973) e ao sucesso de seu livro mais famoso: Geopolítica da Fome (Géopolitique de la faim), publicado em 1952 pelas Éditions ouvrières em Paris. Na verdade, os dois homens se conheciam. Josué de Castro foi Professor do Centro Experimental Universitário de Vincennes (CUEV) - desde a sua fundação em 1968 até o ano da sua morte em 1973. É neste lugar importante do pensamento contestador que ele conheceu o jovem geógrafo Yves Lacoste, recrutado na CUEV em 1969, quando tinha 40 anos $^{3}$. Josué de Castro era então um professor de reputação internacional (quatorze países haviam lhe oferecido asilo político quando fora forçado a deixar o Brasil). O próprio Lacoste descreve o CUEV como:

(...) um lugar de debates estimulantes e discussões inovadoras entre professores de várias disciplinas, ativistas de tendências mais ou menos antagônicas da esquerda e da extrema esquerda (...). (Lacoste, 1985, p. 8).

Pode-se pensar que a proposta de Josué de Castro de usar a palavra "geopolítica" (uma proposição bastante iconoclasta e arriscada em termos de carreira acadêmica na França nos anos 50 ou 60) pode ter influenciado o pensamento geopolítico de Lacoste. Isso ocorre porque ambos usam o mesmo raciocínio para justificar o uso desse termo. Na introdução à Geopolítica da Fome, Josué de Castro explica que ele escolheu a palavra "geopolítica",

(...) Porque não encontramos nada mais que correspondesse sem trair o conteúdo do livro e o desejo dos editores. É por isso que a capa tem uma expressão tão perigosa (...) devido a essa palavra tão comprometida, tão desviada do seu significado essencial, tão contaminada e tão execrada: a geopolítica. Mas, embora degradada pela dialética nazista, a palavra

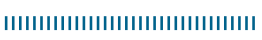

3 Yves Lacoste teria sido recrutado para o CUEV por um comitê de seleção compreendendo o próprio Josué de Casto. Este ponto preciso foi evocado oralmente não estando, entretanto, comprovado. Sobre o CUEV, ver Souilé, 2012. geopolítica ainda mantém seu valor científico e deve ser reabilitada em seu sentido real. Tal reabilitação merece mesmo um sacrifício por parte do autor que se expõe ao perigo de interpretações precipitadas através da simples leitura do título do seu livro.

O significado real da palavra geopolítica é o de uma disciplina científica que procura estabelecer as correlações entre fatores geográficos e fenômenos de natureza política, a fim de demonstrar que as diretrizes políticas não têm sentido fora dos marcos geográficos, isto é, se as separarmos da realidade e das contingências do ambiente natural e do meio cultural. Está claro que a geopolítica assim compreendida não tem nada a ver com a Geopolitik alemã, pseudo ciência de Karl Haushofer (...), é apenas um método de interpretação da dinâmica dos fenômenos políticos em sua realidade espacial (...). (Castro, 1952, p.20-21).

A defesa do uso do termo "geopolítica" por Y. Lacoste na década de 1970 é baseada na mesma lógica de J. de Castro. Como ele escreveu na introdução da $28^{\mathrm{a}}$ edição da revisão de Hérodote para explicar seu novo subtítulo:

(...) Pareceu-nos que o termo "geopolítica”, há muito tempo mantido em descrédito ou suspeito, tornou-se (...) o rótulo de um certo tipo de discurso (...) dito realista, mas que procedem, como outros, de tendências ideológicas (...). Não temos que deixar-lhes o campo livre nem o monopólio do termo geopolítico. É mais do que nunca necessário mostrar que existem formas muito diferentes de tratar os problemas geográficos e geopolíticos. Para aqueles que proclamam que a geopolítica é um "conceito hitleriano", diremos que não é apenas o raciocínio de Ratzel e seus seguidores nazistas que devemos analisar, se queremos combatê-los efetivamente, é também a preocupação do geógrafo libertário Élisée Reclus, a quem tanto admiramos. (Lacoste, 1983, p. 4).

Conforme observado, os dois autores se envolvem em uma reabilitação da geopolítica que tem muitas características comuns, incluindo a de não estar preso ao paradigma "imperialista" de seus fundadores. Como tal, postulamos bem a influência de um sobre o outro, mesmo que isto não tenha sido imediato. Yves Lacoste realmente usou a palavra geopolítica somente a partir do início da década de 1980.

Assim, o nascimento da geopolítica na França na década de 1970 pode ser considerado como uma das consequências da influência do pensamento 
geopolítico no Brasil, mesmo que Lacoste nunca tenha reconhecido a influência de Josué de Castro em seu próprio pensamento. Ao contrário, ele não parou de o atacar repetidamente em muitas ocasiões, até mesmo chamando-o de agente da CIA. (Rosière, 2013a). No entanto, o próprio uso do termo cria um efeito de contexto que não deve ser minimizado.

\section{A fragmentação contemporânea da geografia política e da geopolítica, 0 exemplo francês}

A fragmentação dos pesquisadores que trabalham na interface espaço / política é sensível na França, como em outros países. As posições ideológicas na França parecem representativas do que acontece em muitos outros países. (Antonsich, Kolossov, Pagnini, 2001). Assim, ao descrever o "local", vamos esboçar o "global".

Devido à recepção complicada da geografia política e da geopolítica, a antiga resistência a essas disciplinas nunca desapareceu, mesmo que seja menos forte hoje. Assim, a maioria dos geógrafos franceses ainda preferem, de acordo com Albert Demangeon, recorrer à geografia política, ou geografia pura e simplesmente, em vez de geopolítica. Esta recusa baseia-se antes de tudo em uma certa visão do passado (Haushofer sendo reduzido a um nazista, o que ainda é simplista, conforme as análises relevantes de Lacoste 1995 ou de Ó Tuathail 1996). Esta situação é semelhante à encontrada nos Estados Unidos especialmente. A coisa é menos verdadeira no Brasil, onde, tradicionalmente, o termo "geopolítica" foi implantado há muito tempo e melhor aceito, como evidenciado pelo uso por Josué de Castro - mas, ele não pertencia à escola geopolítica brasileira, pelo contrário.

Os pesquisadores que na França usam o rótulo geopolítico, podem hoje ser divididos em três correntes distintas: aqueles que podem estar relacionadas com a escola "clássica", anti-pósmoderna; aqueles que pertencem à escola mais especificamente francesa lacostiana e a escola “crítica” que tem crescido há 20 anos (cf. 3).
A escola que eu chamo de "clássica" baseiase numa abordagem estritamente estruturalista que procura explicar a política dos estados por um conjunto de fatores objetivos (mobilizando a geografia, mas também a história). Esta escola é representada na França, dentre outros, por Aymeric Chauprade (ex-deputado europeu da Frente Nacional) ou Pascal Gauchon (diretor influente da coleção Presses Universitaires de France e co-diretor do Festival de Geopolítica de Grenoble, a mais importante manifestação desta disciplina na França). Os fundamentos ideológicos desta corrente são nacionalistas e reacionários. Seus partidários estão envolvidos na defesa do Estado ou do Ocidente (da perspectiva de Huntington). O método de Chauprade é "sedimentar", na medida em que se baseia no acúmulo de informações estatísticas na forma de um novo enciclopedismo, e na rejeição de todo pensamento pós-moderno (da esquerda). A título de exemplo, Aymeric Chauprade ataca a noção de "representação" que, segundo ele, funda "uma ciência da ilusão" (cfe. a introdução ao seu livro Geopolítica). Esta corrente é fraca academicamente mas poderosa, transmitida por editores e meios de comunicação, que tenta influenciar a política externa nacional (como o general Golbery fez em seu tempo, tornando-se um "praticante" da geopolítica). Esta corrente não é especificamente francesa, ela existe em todo o mundo, e particularmente nos países que desenvolvem políticas de influência. Para esses geopolíticos, a geopolítica é o breviário do poder pois através desta disciplina buscam uma posição hegemônica para seus países de origem (é uma tradição fundadora desde Ratzel, Haushofer ou MacKinder - todos comprometidos com a defesa de seus países).

A escola lacostiana era totalmente diferente na essência por ser originária na esquerda, da defesa dos povos colonizados (influência de Jean Dresch) e da oposição ao imperialismo americano (Lacoste, 1976). Ao colocar o foco na palavra "geopolítica" no início dos anos 80, ela se opôs na época à "nova geografia”. Nos anos 1970-80, a "nova geografia” encontrou na França, na pessoa de Roger Brunet, um líder e um conceitualizador. 
Para R. Brunet e os "novos geógrafos" (cuja revista emblemática é L'Espace géographique fundada em 1972), a geografia é essencialmente política. Como tal, parecia-lhes inútil desenvolver uma assim chamada geografia "política". Este posicionamento lógico, no entanto, muitas vezes se resumiu a preferir temas econômicos e sociais às questões mais especificamente políticas, nomeadamente as questões de Estado, fronteiras e reivindicações territoriais, temas por longos anos marginais na "nova geografia". A oposição entre essas duas correntes persiste, especialmente entre defensores da geopolítica, muitas vezes ligados à escola lacostiana e partidários da geografia política (Sanguin).

Esta oposição pode ser simbolizada pela competição entre dois periódicos: L'Espace géographique, lançado por Roger Brunet em 1972 e que se tornou uma das principais revistas da geografia francesa, enquanto que, por sua vez, Yves Lacoste lançou a revista Hérodote, em 1976, inicialmente com o subtítulo "Estratégias, geografias, ideologias" e depois ela assume o subtítulo de "Revista de geografia e de geopolítica” em 1983 (n. ${ }^{\circ} 28$ ). Seu objetivo era tornar as questões territoriais debates públicos e dos cidadãos, juntando-se assim a uma das preocupações de K. Haushofer ao lançar o Zeitschrift für Geopolitik, de não ser mais apenas o assunto de negociações secretas entre os poderosos. Essa luta de liderança que durou pelo menos até a década de 2000 manteve a divisão entre os geógrafos, de um lado, e os "geopolíticos", de outro.

Ao contrário do que Roger Brunet ou os "novos geógrafos" argumentaram, ninguém mais contesta a utilidade do rótulo "geografia política" que pode ser descrito como dominante em uma escala global. A influência da geografia política é sublinhada pela forte ancoragem desta subdisciplina na América do Norte. A Escola de Geografia Política dos EUA é antiga (os funcionalistas da década de 1950, personificados por Richard Harsthorne), sendo a revista Political Geography fundada em 1981 como porta-voz desta abordagem. Political Geographyé a principal revista do mundo, bem representada na
União Internacional de Geografia (ver o papel de Vladimir Kolossov, atual presidente da associação, vindo da geografia política).

Ao contrário do que Lacoste queria, a geopolítica não é mais dominante, mas ela não é mais considerada como uma abordagem nazista (observe as exceções de Raffestin, 1995, ou Vandermotten e Vandeburie, 2005). Ela não é nem banida, como já havia sido, e nem é reconhecida em todos os lugares (o Brasil é um caso bastante excepcional). Mas a geopolítica continua frágil em seus fundamentos teóricos. Hoje, falar sobre geopolítica já não é um problema em uma arena acadêmica, ela também tem o seu boletim líder anglo-saxão (Geopolitics, lançado em 1998, portanto muito mais recente que a Political Geography. Ela ressente-se, porém, da marca do longo déficit de legitimidade de uma abordagem que parece ter se tornado respeitável). Mas esta geopolítica é muitas vezes uma geopolítica crítica (cf.3).

A escola lacostiana, hoje simbolizada pelo Instituto Francês de Geopolítica (IFG, de acordo com uma denominação que não tem mais nada de esquerdista ${ }^{4}$ ) não teve a influência que poderia ter tido. Relativamente isolada, a escola lacostiana é freqüentemente apresentada como "radical", ou esquerdista, o que não é mais. A institucionalização do IFG reorientou seu discurso. Seu posicionamento epistemológico permanece original enfatizando a importância das "representações" seguindo uma abordagem totalmente crítica, adiante de seu tempo, enquanto reivindica o uso de mapas cuja escola "crítica" praticamente aboliu o uso. Ligado à análise multiescalar (ou "diatópica" para usar a terminologia lacostiana), esta abordagem se afirma como claramente geográfica, enquanto que a mudança "antropológica" da abordagem crítica tende a deixar pouco espaço para o estudo do espaço (cf.3). Devido à sua posição geográfica, sua posição centrista em termos epistemológicos, esta escola poderia ter tido uma grande influência

||I|||||||||||||||||||||||||||||||||

4 Um Instituto Internacional de Geopolítica, editor da Revista Geopolítica, havia sido fundado em 1982 por Marie-France Garaud. Yves Lacoste funda o Centro de Pesquisa e Análise de Geopolítica (CRAG) em 1980, que se tornou o IFG em 2002. 
internacional, mas além da celebridade de sua figura central, ela sofreu uma abertura fraca para outras correntes de pensamento e toda a evolução científica, especialmente na América do Norte. Assim, Yves Lacoste admitiu em 2010 que falava muito pouco inglês, mas que o trabalho dos geógrafos anglo-saxões não parecia justificar o esforço para se aperfeiçoar nesta linguagem .(Lacoste e Lorot, 2010).

Neste contexto, uma revista como a L'Espace politique $^{5}$ representa uma tentativa de renovação e uma possível saída do conflito entre a "nova geografia" ou a geografia política, por um lado, e a geopolítica, por outro. O próprio nome "espaço político" refere-se claramente ao "espaço", conceito central na nova geografia (a fórmula do espaço político se refere claramente ao L'Espace géographique), mas coloca mais claramente a palavra "Político", como é o caso do neologismo "geopolítico". Ao fazê-lo, a revista L'Espace politique aparece na encruzilhada das escolas francesas.

\section{O predomínio contemporâneo da geopolítica crítica}

Toda ciência evolui em seus temas de pesquisa, conceitos e métodos. O surgimento da geopolítica crítica em 1996 é um dos principais desenvolvimentos recentes da geopolítica. Esta escola tornou-se dominante, especialmente porque é levada por muitos pesquisadores norteamericanos (muitas vezes com base em correntes pós-modernas integradas na "teoria francesa", das quais, deve ser enfatizado, o CUEV foi um lugares principais desde que os filósofos Gilles Deleuze, Michel Foucault, Jean-François Lyotard, Roland Barthes ou François Chatelet ${ }^{6}$ ensinaram lá). A geopolítica crítica foi concebida na América do Norte por pesquisadores europeus, incluindo o trio das ilhas britânicas Simon Dalby, Gearoid Ó Tuathail e John Agnew.

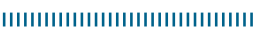

5 A Revista L'Espace Politique, dirigida pelo autor, pode ser acessada em: <http://journals.openedition.org/espacepolitique/>(NT).

6 O filósofo François Châtelet escreveu na Revista Hérodote, cfe. "Hegel e a geografia”, publicado no número 2 de 1976.
A expressão "geopolítica crítica" foi lançada por Simon Dalby (1990) e pode-se dizer que, já em 1996, a abordagem foi reconhecida como evidenciada pela publicação simultânea de uma edição da revista Political Geography que lhe é inteiramente dedicado (Dalby, Ó Tuathail, 1996), e do livro de referência sobre o assunto: Geopolítica crítica (Ó Tuathail, 1996). A abordagem descrita por esses pesquisadores tornou-se amplamente aceita desde então. Esta situação parece ser fruto de um contexto geopolítico: a hegemonia norte-americana (Rosière, 2009). Essa renovação da geopolítica é uma mudança epistemológica completa. Se os fundadores da geopolítica podem ser apresentados como teóricos do imperialismo (Rosière, 2013b), os geopolíticos "críticos" tentam analisar os discursos da hegemonia e se apresentar como anti-imperialistas.

Esta escola é baseada em paradigmas pósmodernos (ou pós-estruturalistas). Por seus métodos, é focada no estudo de "discursos" e representações. Curiosamente, a noção de "representação" (do espaço) se refere diretamente ao trabalho do filósofo Henri Lefebvre (19011991) que foi um dos primeiros a entender o mundo não como uma realidade objetiva, mas sobretudo como um conjunto de subjetividades e visões pessoais em permanente reconstrução. $\mathrm{O}$ seu trabalho central sobre o assunto: $A$ produção do espaço, publicada em Paris em 1974, marcou época e semeou a geopolítica crítica da década de 1990. Gearoid Ó Toothily (1996) se refere claramente aos seus trabalhos, mais conhecidos e mais citados hoje na América do Norte (ou no Brasil) do que na França. No entanto, a noção de representação entrou no vocabulário da geografia francesa na década de 1950, sob a influência dos behavioristas, relacionada aos "comportamentos" dos indivíduos (Bailly, 1984). Um dos primeiros números da revista L'Espace géographique $\left(\mathrm{n}^{\circ} 3,1974\right)$ foi assim dedicada à "percepção do espaço" (Claval, 1974). O geógrafo brasileiro Milton Santos se interessou por essa noção na década de 1990 (Santos, 1997). Y. Lacoste também usa este termo em abundância, tornando-se até uma das suas palavras-chave. Assim, a noção de representação é unânime entre 
geógrafos franceses ou geopolíticos. Apenas os geopolíticos "clássicos" na França refutam o seu uso e pertinência.

A influência da corrente crítica tem sido, portanto, profunda, tanto na geografia como um todo e na geopolítica. A escola crítica está quase em posição de hegemonia (veja o conteúdo da revista Political Geograpahy onde essa abordagem parece ter se tornado dominante). Esta posição é paradoxal para uma abordagem que, em essência, se opõe ao poder estabelecido. Já há dez anos, o geógrafo britânico Nicholas Blomley enfatizava que "à medida que a geografia crítica se expande, corre o risco de perder sua dimensão crítica" (2006, p. 88). No entanto, o domínio não significa homogeneidade. A "pluralização" dos pensamentos críticos já foi destacada, mesmo que as correntes que estão a ela relacionadas permaneçam unidas porque visam "revelar os mecanismos econômicos, políticos e sociais através dos quais a dominação é perpetuada" (Gintrac, 1998, 2012). Abordagens como estudos subalternos se opõem fortemente às teorias geopolíticas globais formuladas pelos fundadores da disciplina. Em menos de um século, o foco passou do global ao indivíduo.

\section{As armadilhas de uma abordagem}

O predomínio do pensamento crítico, no entanto, coloca dois tipos de problemas: a marginalização dos mapas e o risco, concentrandose nas representações, de criar impasses sobre qualquer estudo do espaço concreto.

O mapa tornou-se hoje um objeto marginal nas publicações de geógrafos. O declínio em seu uso foi medido e comentado adequadamente por Eduardo Boria (2013). Os geógrafos críticos estão a ponto de descartar esses documentos percebidos como obsoletos, enquanto, inversamente, o fato de citar muitos filósofos tornou-se necessário em um artigo de geografia. Percebido como uma ferramenta de poder, o mapa nunca parece ser considerado uma ferramenta de "contra-poder". O que os fundadores de Heródote escreveram sobre isto no primeiro número da revista em 1976? Eles enfatizaram (p. 7) o interesse dos mapas para:
Mapear a localização das empresas para frustrar sua mobilidade, desmascarar o planejamento do uso do território, desmascarar as fabricações com a finalidade de reprimir espaços reais ou imaginários, localizar futuras tensões, elaborar uma topologia de dominação.

Esta dimensão "radical" parece ter sido esquecida. No entanto, parece perigoso que os geógrafos desistam do uso desta mídia específica para sua profissão e, portanto, deixando aos outros a sua concepção e a utilização. Os geógrafos são os únicos capazes de analisar os mapas que permanecem produzidos por "praticantes" da geopolítica ou os políticos (como é o caso nos Estados Unidos, onde o mapa é uma ferramenta mais militar do que acadêmica). Enquanto pensamos em termos de planejamento territorial, um tema que interessa aos participantes do $2^{\circ}$ Congresso da Geografia Política brasileira, de luta contra o autoritarismo ou da guerra, o mapa é um vetor de conhecimento e, portanto, de poder. Deste ponto de vista, a tradição francesa, muito rica, toda tradição brasileira, são possíveis pontos de apoio para renovar essa "relação em crise" (Boria 2008) e propor novas orientações científicas.

No segundo ponto, o pensamento "crítico" é uma verdadeira revolução paradigmática (e este foi o objetivo do pensamento pós-moderno), mas quem se interessará pelo espaço em sua dimensão concreta se até mesmo os geógrafos desistirem disto? Se todos os geógrafos estão interessados apenas nas representações, quem irá conduzir os estudos de campo?

Parece difícil realizar uma reflexão operacional e aplicada se alguém se ater somente às representações. Se pensar sobre as representações é necessário (e não possível voltar ao passado), no entanto, ignorar completamente o espaço em sua dimensão objetiva parece perigoso. Se o pensamento do "planejamento" parar, não há mais planejamento e gestão do território. A abordagem crítica torna-se estranhamente liberal a este respeito. Deste ponto de vista também, tanto o Brasil quanto a França possuem fortes tradições de estudo do espaço. Este conhecimento permanece necessário em um mundo onde o espaço concreto parece "desmonetizado", mas 
continua sendo um suporte dos poderes (como explicou Henri Lefebvre).

\section{Conclusão}

Como acabamos de ver, o campo da geografia política e da geopolítica, embora modesto pelo número de pesquisadores envolvidos, permanece altamente fragmentado. Se alguns pesquisadores continuam arraigados sobre as denominações (e proíbem o uso da expressão "geografia política" ou "geopolítica") outros - dos quais eu sou parte consideram os dois termos, senão como sinônimos pelo menos como tendo a mesmo objeto.

A desconstrução do nome da revista L'Espace politique é ilustrativa: ao escolher "espaço", nos referimos à hashtag da "nova geografia", enfatizando o "político", lembramos o propósito de uma abordagem. Quando, em 2007, a L'Espace politique na sua fundação, obteve o subtítulo de "revista de geografia política e geopolítica", ressaltou-se o desejo da equipe editorial de ir além das velhas divisões e das guerras de trincheiras universitárias (francesas mas não somente essas) da década de 1990. Nenhum dos pesquisadores percebeu no nome da L'Espace politique uma provocação. Ela existia sim, bem discretamente, eu o assumo, mas não se tratava de declaração de guerra à uma escola ou outra, mas um apelo implícito para superar antigas divisões.

Nesta paisagem academicamente fragmentada, as pontes são coisas boas. Em 2017 - vou anunciar em outro momento - o número da revista L'Espace Politique será dedicado ao pensamento geopolítico no Brasil, sob a direção de Gutemberg Vilhena da Silva e Hervé Théry?. Este número, que irá destacar a força do pensamento geopolítico no Brasil, terá como objetivo estratégico o de promover as pontes entre os dois países para vivermos uma pluralidade de abordagens em um mundo que permanece plural.

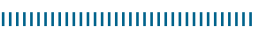

7 O número especial da revista L'Espace Politique dedicado à geopolítica brasileira foi publicado no número $31 \mathrm{em}$ 2017. Disponível em: <http://journals.openedition.org/ espacepolitique/4110>

\section{Referências}

ALBUQUERQUE, E. S. de. Uma breve história da Geopolítica. Rio: CENEGRI, 2011.

ANCEL, J. Géographie des frontières. Paris : Gallimard, 1939.

ANTONSICH, M.; Kolossov, V.; Pagnini, M.P. (Eds.) On the centenary of Ratzel's Politische Geographie, Europe between political geography and geopolitics. Roma: Societa Geographica Italiana, 2001.

BACKHAUSER, E. Problemas do Brasil (Estrutura Geopolítica). O "espaço". Rio de Janeiro: Omnia, 1933.

BAILLY, A. La géographie des représentations : espace perçus et espaces vécus. In : Bailly A. (Ed.), Les concepts de la géographie humaine. Paris: Masson, p.133-138, 1984.

BLOMLEY, N. "Uncritical critical geography?" Progress in Human Geography, v. 30, n. 1, p. 87-94, 2006.

BOHOU, J.-M. Géopolitique et projection de puissance du Brésil au XXIe siècle. Paris: Éditions L'Harmattan, 2007.

BORIA, E. Geographers and Maps: A Relationship in Crisis. L'Espace Politique [En ligne], 21 | 2013-3, mis en ligne le 12 décembre 2013, consulté le 10 avril 2017. Disponível em: <http://espacepolitique.revues. org/2802 ; DOI: 10.4000/espacepolitique.2802>.

CASTRO, J. de. Géopolitique de la faim. Paris: Éditions Ouvrières, 1952.

CLAVAL, P. La perception de l'espace. L'Espace géographique, n³, p. 179-187, 1974. [En ligne] Consulté le 15 février 2017, Disponível em: <http://www.persee.fr/doc/ spgeo_0046-2497_1974_num_3_3_1479>.

COSTA (da), W. M. Geografia politica e geopolitica. Discursos sobre o territorio e o poder. São Paulo: Hucitec/Edusp, 1992.

DELGADO DE CARVALHO, C. Introdução à Geografia Política. Rio de Janeiro: Francisco Alves, 1929.

DALBY, S. Creating the Second Cold War: The Discourse of Politics. London/New York: Pinter Publishers/Guilford Press, 1990.

DALBY, S.; Ó Tuathail, G. "Critical Geopolitics". Political Geography, special issue, v. 15, .n 6-7, p. 451-665, 1996.

GEORGE, P. Introduction à l'étude géographique de la population du monde. Paris: Presses universitaires de France, 1951.

GEORGE, P.; Guglielmo, R.; Kayser, B.; Lacoste Y. La Geographie Active. Paris: Presses Universitaires de France, 1964.

GINTRAC, C. Géographie critique, géographie radicale : Comment nommer la géographie engagée ? Carnets de géographes, $n^{\circ} 4,2012$. [En ligne] Consulté le 30 janvier 2017. Disponível em: <http://www.carnetsdegeographes. org/carnets_recherches/rech_04_04_Gintrac.php >.

GOTTMAN, J. La politique des Etats et leur géographie. Paris: Armand Colin, 1952.

LACOSTE, Y., Enquête sur les bombardements des digues du Fleuve rouge, Hérodote, nº 1, p. 86-117, 1976.

LACOSTE, Y., Editorial. Paris : Hérodote, n. 28, p. 3-5, 1983. 
LACOSTE, Y. La géographie, ça sert d'abord à faire la guerre. Paris: La Découverte, deuxième édition, 1985.

LACOSTE, Y. ; Lorot P. La géopolitique et le géographe. Entretiens avec Pascal Lorot. Paris: Choiseul Éditions, 2010.

LEFEBVRE, H. La production de l'espace. Paris: EconomicaAnthropos, 1974.

Ó TUATHAIL, G. Critical Geopolitics: The Politics of Writing Global Space. Minneapolis: University of Minnesota, 1996.

Ó TUATHAIL, G.; Agnew, J. Geopolitics and Discourses. Practical geopoliting reasoning in American foreign policy, Political Geography, v. 11, n² 2, p.190-204, 1992.

RAFFESTIN, C. ; Lopreno, D. ; Pasteur, Y. Géopolitique et histoire. Lausanne: Payot, 1995.

ROSIÈRE, S. « L'espace politique, quels concepts et quelles échelles? » In: S. Rosière, K. Cox, C. Vacchiani-Marcuzzo, C. Dahlman (Eds.), Penser l'espace politique. Paris: Ellipses, p. 17-33, 2009.

ROSIÈRE, S. La géopolitique au Brésil. Importation et réexportation d'une discipline controversée. In: M. Bazin, C. Fournet-Guérin et $\mathrm{S}$. Rosière (Eds.). De Récife à Reims, récits géographiques. Mélanges offerts à Pernette Grandjean. Reims : Épure, p. 155-185, $2013 a$.

ROSIÈRE, S. Géopolitiques contemporaines. Des théories impérialistes à la critique de l'hégémonie, Prague, Kamil Mař́k Professional Publishing, 2013b.

SANGUIN.A.-L. Vidal de la Blache et la géographie politique. Bulletin de l'Association de Géographes Français, vol.65, n 4, p.321-331, 1988.

SANTOS, M. La nature de l'espace : technique et temps, raison et émotion. Paris: Éditions L'Harmattan, 1997.

SIEGFRIED, A. Tableau politique de la France de l'Ouest sous la Troisième République. Paris: Armand Colin, 1913.

SOULIÉ, C. (Ed.) Un mythe à détruire ? Origines et destin du centre expérimental de Vincennes. Saint-Denis : Presses Universitaires de Vincennes, 2012

VANDERMOTTEN, C. ; Vandeburie, J. Territorialité et territoires. Bruxelles: Presses de l'Université Libre de Bruxelles, 2005.

\section{Stéphane Rosière}

Professor na Universidade de Reims. Pesquisador do Laboratório Habiter (EA.2076). Diretor do Mestrado em Geopolítica de Reims e da Revista L’Espace Politique.

E-mail: stephane.rosiere@univ-reims.fr 